\title{
LY294002, an inhibitor of PI-3K, enhances heat sensitivity independently of p53 status in human lung cancer cells
}

\author{
KEN OHNISHI ${ }^{1}$, JUN-ICHI YASUMOTO ${ }^{2}$, AKIHISA TAKAHASHI ${ }^{1}$ and TAKEO OHNISHI $^{1}$ \\ Departments of ${ }^{1}$ Biology and ${ }^{2}$ Oral and Maxillofacial Surgery, Nara Medical University \\ School of Medicine, 840 Shijo-cho, Kashihara, Nara 634-8521, Japan
}

Received December 15, 2005; Accepted February 13, 2006

\begin{abstract}
The aim of this study was to ascertain whether LY294002, an inhibitor of PI-3K, enhances heat sensitivity in human cancer cells regardless of their p53 status. Colony formation assays showed that LY294002 enhanced heat sensitivity in two human lung cancer cell lines; H1299/wildtype $p 53$ (wtp53) and H1299/mutated p53 (mp53) cells. These cell lines have identical genetic backgrounds except for their p53 status. LY294002 suppressed the heat-induced accumulation of heat shock protein 27 (hsp27) and heat shock protein 72 (hsp72) in these cell lines. Heat-induced apoptosis was observed more frequently in H1299/wtp53 cells than in H1299/mp53 cells, and was enhanced by LY294002 in both cell lines. In addition, both the heat-induced phosphorylation of Akt and the accumulation of survivin were suppressed by LY294002. These results suggest that LY294002 inhibits anti-apoptosis signaling through hsp27 and hsp72 as well as cell survival signaling through Akt and survivin. LY294002 appears to be an attractive candidate for a p53-independent heat sensitizer in hyperthermic cancer therapy.
\end{abstract}

\section{Introduction}

Hyperthermia can be an effective cancer therapy $(1,2)$. However, to develop more efficient regimens for using heat to treat various malignant tumors, agents are required which can sensitize cancer cells to heat. Apoptosis is a beneficial physiological response resulting in cell death without inflammation. Molecular biological studies have examined the heat-induced signal transduction pathway for apoptosis operating through p53 (3) and/or c-Jun N-terminal kinase (JNK) $(4,5)$. However, heat also activates signal transduction pathways for anti-apoptosis/cellular proliferation activity. Several signaling factors such as Akt, p38, extracellular signal-regulated kinase (ERK) and heat shock protein

Correspondence to: Dr Takeo Ohnishi, Department of Biology, Nara Medical University School of Medicine, Kashihara, Nara 634-8521, Japan

E-mail: tohnishi@naramed-u.ac.jp

Key words: heat, apoptosis, inhibitor, LY294002, p53 (hsp) play important roles in the anti-apoptosis/cellular proliferation pathway (4,6-15). Since active signaling pathways mediated by such factors can reduce the efficacy of hyperthermic cancer therapy, the targeted inhibition of antiapoptosis/cellular proliferation signaling factors could be useful for the development of potent hyperthermic cancer therapies.

A serine/threonine kinase, Akt, is known to mediate many biological processes which affect anti-apoptotic/cell survival responses $(14,15)$. Amplification of the Akt gene is frequently observed in various types of cancer cells. The activity of Akt is high in cancer cells defective in the phosphatase and tensin homologue deleted on chromosome 10 (PTEN) which downregulates Akt activity. These abnormalities of Akt expression are considered to be closely related to tumorigenesis. Thus, Akt is now becoming a promising and attractive molecular target for enhancing apoptosis (16) and for cancer therapy (17). Akt is activated by heat as well as radiation through a phosphatidylinositol-3-kinase (PI3-K) mediated phosphorylation pathway (18). LY294002 is known to be a specific inhibitor of PI-3K (19), and radio-sensitization caused by LY294002 has been reported in in vitro (20) and in vivo experiments (21). In contrast to this, the effects of LY294002 on heat sensitization have not been examined. This study examined the effects of LY294002 on heat sensitivity in two human lung cancer cell lines which differed only in their p53 status.

This study also examined the effects of LY294002 on the heat-induced accumulation of hsp27 and hsp72 which are involved in anti-apoptosis signaling pathways (6-12). The effects of LY294002 on heat sensitivity are discussed in relation to the functions of hsp27 and hsp72 in anti-apoptosis signaling pathways.

\section{Materials and methods}

Cell culture. Human lung cancer H1299 cells (p53-null) were a gift from Dr M. Oren, Weizmann Institute of Science, Rehovot, Israel. These cells were transfected with either pC53SN3 containing the wt $p 53$ gene, or with pC53-248 containing the mp53 gene (Arg to Trp at codon 248). The transcription of the wtp53 or the mp53 gene was confirmed in stable clones of these cells using RT-PCR RFLP, and the translation of the p53 protein was confirmed using Western blot analysis (22). The cell lines were cultured at $37^{\circ} \mathrm{C}$ in Dulbecco's modified Eagle's medium (ICN Biomedicals, Aurora, $\mathrm{OH}$ ) containing 10\% (v/v) 
fetal bovine serum (ICN Biomedicals), penicillin $(50 \mathrm{U} / \mathrm{ml}$; Sigma, St. Louis, MO), streptomycin (50 $\mu \mathrm{g} / \mathrm{ml}$; Meiji, Tokyo, Japan) and kanamycin (50 $\mu \mathrm{g} / \mathrm{ml}$; Meiji) (DMEM-10). Heating was performed by immersing $25-\mathrm{cm}^{2}$ flasks containing the cells into a circulating water bath (TAITEC, Saitama, Japan) at $44^{\circ} \mathrm{C}$ and then incubating them for the indicated periods at $37^{\circ} \mathrm{C}$. X-ray irradiation was performed with a $150-\mathrm{kVp} \mathrm{X}$-ray generator (Model MBR-1520R, Hitachi, Tokyo, Japan).

LY294002 treatment. LY294002 (at a final concentration of $40 \mu \mathrm{M}$ ) was added to the culture media one hour before heat or X-ray treatment.

Colony formation assay. The fraction of surviving cells after heat exposure or X-ray irradiation was determined using a clonogenic assay; the number of colonies for each treatment point was corrected using the plating efficiency $(\sim 75 \%)$ of the non-treated cells as a control. A total of $5 \times 10^{2}$ or $1 \times 10^{3}$ cells were plated in each of two T25 flasks per experiment, and three independent experiments were performed for each survival point. Cells were heated or irradiated and, after 14 days of incubation, visible colonies composed of more than 50 cells were counted. Colonies were fixed with $100 \%$ methanol for a few minutes and stained with a $2 \%$ Giemsa solution (Merck \& Co., Inc., Rahway, NJ). Each colony was scored as having grown from a single surviving cell. The values obtained were expressed as the means of three independent experiments; bars (standard errors) are shown when the standard errors exceed the values indicated by the symbols.

Western blot analysis. A total of $5 \times 10^{5}$ cells was resuspended in $50 \mu \mathrm{l}$ RIPA buffer (50 mM Tris, $\mathrm{pH} 7.2,150 \mathrm{mM} \mathrm{NaCl}$, $1 \%$ NP-40, $1 \%$ sodium deoxycholate, and $0.05 \%$ SDS) and then subjected to freezing at $-30^{\circ} \mathrm{C}$ and thawing (on ice) successively three times. Total protein extracts were prepared from non-irradiated control cells or heated cells incubated at $37^{\circ} \mathrm{C}$ for 0,12 , or $24 \mathrm{~h}$ after heating according to experimental procedures. The sample at $0 \mathrm{~h}$ was prepared from heated cells immediately after heating. The protein levels in the supernatants obtained after centrifugation $(15,000 \mathrm{x}$ g) were quantified using a Bio-Rad protein assay kit (Bio-Rad Laboratories, Richmond, CA). Aliquots of proteins $(20 \mu \mathrm{g})$ were analyzed using Western blotting. After electrophoresis on 10 or $15 \%$ polyacrylamide gels containing $0.1 \%$ SDS, the proteins were transferred onto Poly Screen PVDF membranes using an electro-blot BLAST ${ }^{\circledR}$ blotting amplification system (DuPont/Biotechnology Systems, NEN Research Products). The membranes were then incubated with an appropriate antibody: anti-Akt phosphorylated at threonine 308 polyclonal antibody (Cell Signaling Technology, Inc., Beverly, MA), anti-survivin monoclonal antibody (Santa Cruz Biotechnology Inc., Santa Cruz, CA), anti-hsp27 monoclonal antibody (Ab-1, Oncogene Science, Inc., Uniondale, NY), anti-hsp72 monoclonal antibody (SPA-810, StressGen, Victoria, Canada), or heat shock factor 1 (HSF1) polyclonal antibody (SPA-901, StressGen). For visualization of the bands, a horseradish peroxidase-conjugated anti-mouse $\operatorname{IgG}$ antibody (Amersham Pharmacia Biotech Inc., Piscataway, NJ) was used for anti-hsp27 and anti-hsp72, and a horseradish peroxidaseconjugated anti-rabbit IgG antibody (Amersham) was used for anti-phospho-Akt, anti-survivin and anti-HSF1.
Gel mobility-shift assay. Cells $\left(\sim 2 \times 10^{7}\right.$ cells $)$ were heated at $44^{\circ} \mathrm{C}$ for $50 \mathrm{~min}$ in the presence or absence of LY294002 $(40 \mu \mathrm{M})$. Nuclear extracts were prepared at appropriate times after heating as previously described (23). The binding activity of HSF1 to heat shock elements (HSE) was measured by a gel mobility-shift assay using a synthetic double-stranded DNA fragment encoding the hsp72 HSE (5'-CTAGAAGCTT CTAGAAGCTTCTAG-3', Japan Bioservice, Niiza, Saitama, Japan) based on a specific sequence located upstream of the hsp genes $(24,25)$.

Analysis of apoptosis. For detection of apoptotic bodies, cells were fixed with $1 \%$ glutaraldehyde (Nakalai Tesque, Kyoto, Japan) in PBS at $4^{\circ} \mathrm{C}$, washed with PBS, stained with $0.2 \mathrm{mM}$ Hoechst 33342 (Sigma Chemical Co.), and then observed under a fluorescence microscope.

\section{Results}

Effect of LY294002 on heat sensitivity. LY294002 treatment alone showed almost no toxicity in a concentration range from 0 to $50 \mu \mathrm{M}$ in $\mathrm{H} 1299 / \mathrm{wtp} 53$ and $\mathrm{H} 1299 / \mathrm{mp} 53$ cells. In view of this, LY294002 was used at a non-toxic concentration of $40 \mu \mathrm{M}$ in all subsequent experiments. The sensitivity of H1299/wtp53 and H1299/mp53 cells to heat or X-rays was measured using colony formation assays. The surviving fractions of both cell lines treated with LY294002 decreased as the heating period or dose of X-rays increased. Fig. 1 shows the sensitization rate in response to heat or $\mathrm{X}$-rays. The sensitization rates were calculated from doses producing a $10 \%$ survival rate in H1299/wtp53 cells (1.40 in heat, 1.67 in X-rays) and H1299/mp53 cells (1.88 in heat, 1.71 in X-rays). LY294002 thus increased heat sensitivity as well as X-ray sensitivity regardless of $p 53$ status.

Effect of LY294002 on expression of Hsp27, Hsp72 and survivin, and the phosphorylation of Akt. Western blotting was used to examine the effects of LY294002 on the heatinduced accumulation of hsp27 and hsp72 after heating. As shown in Fig. 2, an accumulation of hsp27 and 72 proteins was observed at $12 \mathrm{~h}$ after heating in H1299/wtp53 and H1299/mp53 cells. In both cell lines treated with LY294002, the accumulation of these proteins was suppressed. The suppressive effect of LY294002 on heat-induced hsp accumulation was somewhat stronger for hsp27 than for hsp72 in both cell lines. After LY294002 treatment alone, there was no sign of increased hsp27 and hsp72 levels at 12 and $24 \mathrm{~h}$ after treatment (data not shown). The effects of LY294002 on the heat-induced phosphorylation of Akt and expression of the downstream factor survivin were also examined using Western blotting. As shown in Fig. 2, Akt phosphorylated at threonine 308 was observed at $12 \mathrm{~h}$ after heating, and constitutive expression of survivin was apparent in both H1299/wtp53 and H1299/mp53 cells. In both cell lines, after treatment with LY294002, the phosphorylation of Akt and the expression of survivin were suppressed. However, after LY294002 treatment alone, there was no sign of increased phosphorylated Akt and survivin 12 and $24 \mathrm{~h}$ after treatment (data not shown).

Effect of LY294002 on DNA binding activity of HSF1. To examine the effect of LY294002 on hsp gene expression, the 


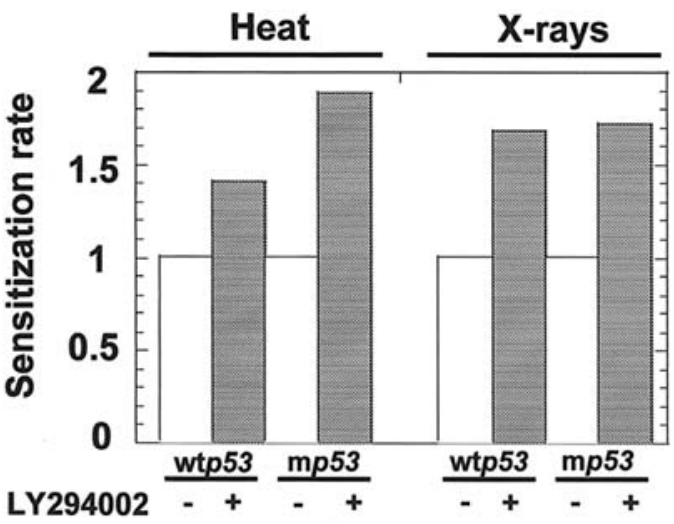

Figure 1. Effects of LY294002 on cellular sensitivity to heat or X-rays. The sensitization rate to heat or X-rays by LY294002 was calculated from doses producing a 10\% survival rate in H1299/wtp53 and H1299/mp53 cells which are labeled as wt $p 53$ and $\mathrm{m} p 53$, respectively.

a

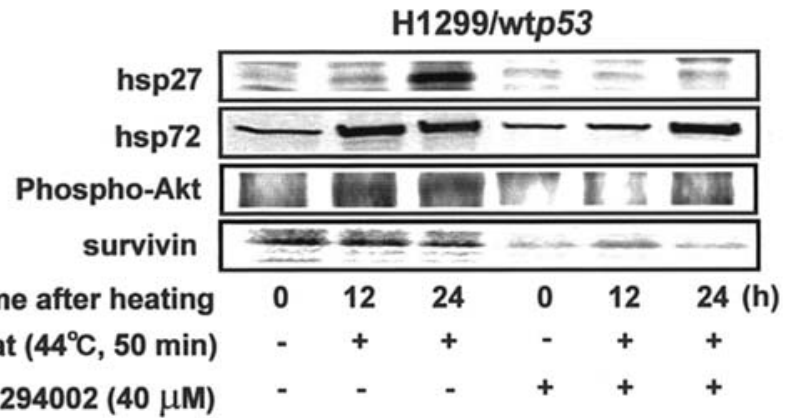

b

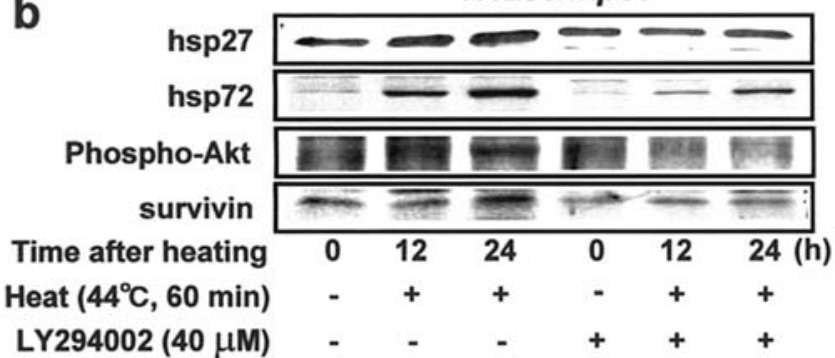

Figure 2. Effects of LY294002 on the expression of hsp27, hsp72 and survivin, and phosphorylation of Akt after heating. The cells were heated under conditions which resulted in a $\mathrm{D}_{10}$ survival rate: $44^{\circ} \mathrm{C}$ for $50 \mathrm{~min}$ (H1299/wtp53 cells) and $44^{\circ} \mathrm{C}$ for $60 \mathrm{~min}$ (H1299/mp53 cells). Whole cell proteins were extracted 0,12 or $24 \mathrm{~h}$ after heating with or without LY294002 $(40 \mu \mathrm{M})$ and analyzed using Western blotting.

DNA binding activity of HSF1 for HSE sequences of hsp72 was measured in nuclear proteins extracted from H1299/wtp53 and H1299/mp53 cells using gel mobility-shift assay (Fig. 3). The amount of HSF1/hsp72HSE complex increased in both cell lines $6 \mathrm{~h}$ after heating. When the cells from both lines were treated with LY294002, the amount of HSF1/hsp72HSE complex decreased after heating. When cold probes for hsp72HSE were added to a mixture of [ $\left.{ }^{32} \mathrm{P}\right]$-labeled hsp72HSE and extracts from both cell lines, HSF1/hsp72HSE complexes were not detected (data not shown). The cellular amounts of HSF1 in both cell lines did not change after heating and were not affected by LY294002 (Fig. 3, lower row).
H1299/wtp53 H1299/mp53

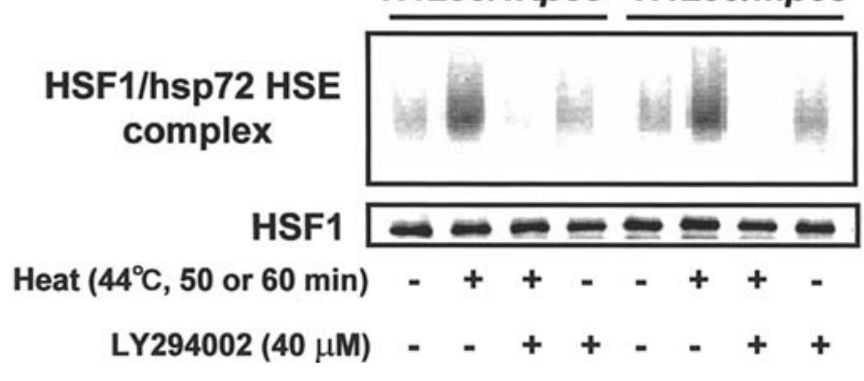

Figure 3. Effects of LY294002 on the binding activity of HSF1 to hsp72HSE before or after heating. The cells were heated (H1299/wtp53 cells, $44^{\circ} \mathrm{C}$ for $50 \mathrm{~min}$; H1299/mp53 cells, $44^{\circ} \mathrm{C}$ for $60 \mathrm{~min}$ ) with or without LY294002 (40 $\mu \mathrm{M})$. Nuclear fractions were extracted $6 \mathrm{~h}$ after heating and analyzed with gel mobility-shift assay.

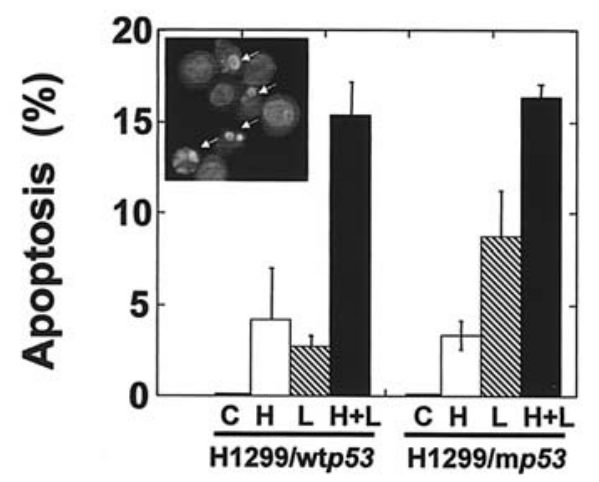

Figure 4. Effects of LY294002 on heat-induced apoptosis. H1299/wtp53 and $\mathrm{H} 1299 / \mathrm{mp} 53$ cells were heated for $50 \mathrm{~min}$ and $60 \mathrm{~min}$ at $44^{\circ} \mathrm{C}$, respectively and incubated for $24 \mathrm{~h}$ at $37^{\circ} \mathrm{C}$. After incubation, apoptotic bodies were detected by Hoechst 33342 staining. Open bars, heat $(\mathrm{H})$; shaded bars, LY294002 $(40 \mu \mathrm{M})(\mathrm{L})$; closed bars, heat + LY294002 $(\mathrm{H}+\mathrm{L})$. C is unheated control. Inset photograph shows apoptotic bodies indicated by arrows.

Effect of LY294002 on heat-induced apoptosis. We examined the induction of apoptosis in order to elucidate the mechanism of enhancement of heat sensitivity by LY294002 in H1299/ wtp53 and H1299/mp53 cells. Nuclear morphology was analyzed with Hoechst 33342 staining and the number of apoptotic bodies, such as those indicated by arrows in the insert in Fig. 4, was scored. The incidence of apoptosis $24 \mathrm{~h}$ after treatment with either heat or LY294002 alone was approximately 3\% in H1299/wtp53 cells, and approximately $3 \%$ (heat alone) and 8\% (LY294002 alone) in H1299/mp53 cells, respectively. The combined treatment with heat and LY294002 enhanced the incidence of apoptosis to approximately $15 \%$ in H1299/wtp53 cells and to approximately $17 \%$ in $\mathrm{H} 1299 / \mathrm{mp} 53$ cells.

\section{Discussion}

In hyperthermic cancer therapy, it is helpful to inhibit signaling factors related to the survival of cancer cells. Although LY294002 has been reported to be a radiation sensitizer which interferes with PI-3K and PI-3K-regulated Akt signaling pathways $(20,21)$, it has not been reported to be a heat 
sensitizer. It was shown here that LY294002 sensitizes cancer cells to hyperthermia as well as to radiation (Fig. 1). LY294002 inhibited heat-induced hsp27 and hsp72 accumulation as well as heat-induced activation of Akt (Fig. 2). These results suggest that LY294002 interferes with heatactivated anti-apoptosis signaling pathways via hsps and/or heat-activated cellular survival signaling pathways via Akt, and consequently enhances the sensitivity of H1299/wtp53 and $\mathrm{H} 1299 / \mathrm{mp} 53$ cells to heat.

It is known that hsp27 and hsp72 play inhibitory roles in various signal transduction pathways involved in apoptosis. Hsps bind to cytochrome c released from mitochondria, and block the binding of cytochrome c to apoptosis proteaseactivating factor-1 (Apaf-1) (6,7). Consequently, the apoptosome, a complex of Apaf-1, caspase- 9 and cytochrome $\mathrm{c}$ is not formed. Since the apoptosome activates caspase-3 $(26,27)$, interference with apoptosome formation could inhibit caspase- 3 activation. Other anti-apoptotic functions of hsp27 are to regulate the activity of Akt (8) and to modulate the metabolism of glutathione, resulting in radioresistance (12). Hsp72 also suppresses heat-induced apoptosis by inactivating JNK $(4,9,10)$ or by antagonizing apoptosis-inducing factor (AIF) (28). The work reported here shows that LY294002 decreased the cellular amounts of hsp27 and hsp72 after heating and increased heatinduced apoptosis in H1299/wtp53 and H1299/mp53 cells (Figs. 2 and 4). In agreement with the increased heat-induced apoptosis observed after exposure to LY294002, the phosphorylation of Akt and expression of survivin were inhibited by LY294002. The LY294002-induced defect in cell proliferation signaling via Akt and survivin appears likely to be a another possible cause of the observed enhanced heat sensitivity.

The results from the gel mobility-shift assay (Fig. 3) correlated well with those from Western blotting. Since HSF1 binding to DNA up-regulates the transcription of $h s p$ gene expression, the suppression of heat-induced accumulation of hsp72 by LY294002 appears to be due to the suppression of HSF1 DNA binding activity. The suppression of HSF1 binding activity to HSE does not result from a decreased amount of HSF1 present in response to LY294002 because the level of HSF1 is not affected by LY294002 (lower row of Fig. 3). HSF1 is activated through phosphorylation and then forms trimers and binds to the HSE sequences located on hsp genes (29-32). A possible explanation of the effect of LY294002 is that it may inhibit the phosphorylation of HSF1 after heating, or block the trimerization of HSF1.

p53 is a tumor suppressor gene that exerts multiple effects via the regulation of numerous genes which are closely related to apoptosis or growth arrest in cells. It has been suggested that p53 status is a predictive indicator of the success of radiation therapy for patients with squamous cell carcinoma of the cervix (33). p53-dependent heat sensitivity has also been reported in human squamous cell carcinoma cells (3). Heat activates p53 and elevates its DNA-binding potential (3). This, together with other reports $(34,35)$, suggests that the effectiveness of hyperthermic cancer therapy could be closely related to $p 53$ staus (36). In this study, the question examined was whether the effects of LY294002 on heat sensitivity depend on p53 status in H1299 cells transfected with wtp53 or $\mathrm{mp53}$; it was found that LY294002 enhanced heat sensitivity in human cancer cell lines in a manner which did not depend on cellular p53 status. From this result, LY294002 would appear to be a good candidate for heat sensitization in hyperthermic cancer therapy, regardless of cellular p53 gene status.

\section{Acknowledgments}

This work was supported by Grants-in-Aid from the Ministry of Education, Science, Sports, Culture and Technology of Japan.

\section{References}

1. Van der Zee J: Heating the patient: a promising approach? Ann Oncol 13: 1173-1184, 2002.

2. Van der Zee J and Gonzalez GD: The Dutch Deep Hyperthermia Trial: results in cervical cancer. Int J Hyperthermia 18: 1-12, 2002.

3. Ota I, Ohnishi K, Takahashi A, et al: Transfection with mutant p53 gene inhibits heat-induced apoptosis in a head and neck cell line of human squamous cell carcinoma. J Radiat Oncol Biol Phys 47: 495-501, 2000.

4. Mosser DD, Caron AW, Bourget L, Denis-Larose C and Massie B: Role of the human heat shock protein hsp70 in protection against stress-induced apoptosis. Mol Cell Biol 17: 5317-5327, 1997.

5. Enomoto A, Suzuki N, Liu C, et al: Involvement of c-Jun NH2terminal kinase-1 in heat-induced apoptotic cell death of human monoblastic leukaemia U937 cells. Int J Radiat Biol 77: 867-874, 2001.

6. Bruey JM, Ducasse C, Bonniaud P, et al: Hsp27 negatively regulates cell death by interacting with cytochrome c. Nat Cell Biol 2: 645-652, 2000.

7. Steel R, Doherty JP, Buzzard K, Clemons N, Hawkins CJ and Anderson RL: Hsp72 inhibits apoptosis upstream of the mitochondria and not through interactions with Apaf-1. J Biol Chem 279: 51490-51499, 2004

8. Rane MJ, Pan Y, Singh S, et al: Heat shock protein 27 controls apoptosis by regulating Akt activation. J Biol Chem 278: 27828-27835, 2003.

9. Li CY, Lee JS, Ko YG, Kim JI and Seo JS: Heat shock protein 70 inhibits apoptosis downstream of cytochrome c release and upstream of caspase-3 activation. J Biol Chem 275: 25665-25671, 2000

10. Meriin AB, Yaglom JA, Gabai VL, et al: Protein-damaging stresses activate c-Jun N-terminal kinase via inhibition of its dephosphorylation: a novel pathway controlled by HSP72. Mol Cell Biol 19: 2547-2555, 1999.

11. Ravagnan L, Gurbuxani S, Susin SA, et al: Heat-shock protein 70 antagonizes apoptosis-inducing factor. Nat Cell Biol 3: 839-843, 2001.

12. Baek SH, Min JN, Park EM, Han MY, Lee YS, Lee YJ and Park YM: Role of small heat shock protein HSP25 in radioresistance and glutathione-redox cycle. J Cell Physiol 183: 100-107, 2000.

13. Cardone MH, Roy N, Stennicke HR, et al: Regulation of cell death protease caspase- 9 by phosphorylation. Science 282: 1318-1321, 1998

14. Del Peso L, Gonzalez-Garcia M, Page C, Herrera R and Nunez G: Interleukin-3-induced phosphorylation of BAD through the protein kinase Akt. Science 278: 687-689, 1997.

15. Datta SR, Dudek H, Tao X, Masters S, Fu H, Gotoh Y and Greenberg ME: Akt phosphorylation of BAD couples survival signals to the cell-intrinsic death machinery. Cell 91: 231-241, 1997.

16. Bang OS, Ha BG, Park EK and Kang SS: Activation of Akt is induced by heat shock and involved in suppression of heatshock-induced apoptosis of NIH3T3 cells. Biochem Biophys Res Commun 278: 306-311, 2000.

17. Fujita $\mathrm{N}$ and Tsuruo T: Survival-signaling pathway as a promising target for cancer chemotherapy. Cancer Chemother Pharmacol 52: S24-S28, 2003.

18. Shaw M, Cohen $\mathrm{P}$ and Alessi DR: The activation of protein kinase $\mathrm{B}$ by $\mathrm{H}_{2} \mathrm{O}_{2}$ or heat shock is mediated by phosphoinositide 3-kinase and not by mitogen-activated protein kinase-activated protein kinase-2. Biochem J 336: 241-246, 1998.

19. Vlahos CJ, Matter WF, Hui KY and Brown RF: A specific inhibitor of phosphatidylinositol 3-kinase, 2-(4-morpholinyl)-8phenyl-4H-1-benzopyran-4-one (LY294002). J Biol Chem 269: 5241-5248, 1994. 
20. Rosenzweig KE, Youmell MB, Palayoor ST and Price BD: Radiosensitization of human tumor cells by the phosphatidylinositol 3-kinase inhibitors wortmannin and LY294002 correlates with inhibition of DNA-dependant protein kinase and prolonged G2-M delay. Clin Cancer Res 3: 1149-1156, 1997.

21. Gupta AK, Cerniglia GJ, Mick R, Ahmed MS, Bakanauskas VJ, Muschel RJ and McKenna WG: Radiation sensitization of human cancer cells in vivo by inhibiting the activity of PI3K using LY294002. Int J Radiat Oncol Biol Phys 56: 846-853, 2003.

22. Takahashi A, Matsumoto H, Yuki K, et al: High-LET radiation enhanced apoptosis but not necrosis regardless of $p 53$ status. Int J Radiat Oncol Biol Phys 60: 591-597, 2004.

23. Ohnishi K, Ohta I, Takahashi A and Ohnishi T: Glycerol restores p53 dependent radiosensitivity of human head and neck cancer cells bearing mutant. Br J Cancer 83: 1735-1739, 2000.

24. Lee YJ, Galoforo SS, Berns CM, et al: Dual effect of 1 alpha,25-dihydroxyvitamin D3 on hsp28 and PKC beta gene expression in phorbol ester-resistant human myeloid HL-525 leukemic cells. Biochem Pharmacol 52: 311-319, 1996.

25. Ohnishi K, Matsumoto H, Takahashi A, et al: Heat shock transcription factor, HSF, is activated by ultraviolet irradiation. Photochem Photobiol 64: 949-952, 1996.

26. Srinivasula SM, Ahmad M, Fernandes-Alnemri T and Alnemri ES: Autoactivation of procaspase- 9 by Apaf-1-mediated oligomerization. Mol Cell 1: 949-957, 1998.

27. Slee EA, Harte MT, Kluck RM, et al: Ordering the cytochrome c-initiated caspase cascade: hierarchical activation of Caspases-2, $-3,-6,-7,-8$, and -10 in a Caspase-9-dependent manner. J Cell Biol 144: 281-292, 1999.

28. Gurbuxani S, Schmitt E, Cande C, et al: Heat shock protein 70 binding inhibits the nuclear import of apoptosis-inducing factor. Oncogene 22: 6669-6678, 2003.
29. Kim D, Ouyang H and Li GC: Heat shock protein hsp70 accelerates the recovery of heat-shocked mammalian cells through its modulation of heat shock transcription factor HSF1. Proc Natl Acad Sci USA 92: 2126-2130, 1995.

30. Larson JS, Schuetz TJ and Kingston RE: Activation in vitro of sequence-specific DNA binding by a human regulatory factor. Nature 335: 372-375, 1988.

31. Lis J and Wu C: Protein traffic on the heat shock promoter: parking, stalling, and trucking along. Cell 74: 1-4, 1993.

32. Sarge KD, Murphy SP and Morimoto RI: Activation of heat shock gene transcription by heat shock factor 1 involves oligomerization, acquisition of DNA-binding activity, and nuclear localization and can occur in the absence of stress. Mol Cell Biol 1: 1392-1407, 1993.

33. Ishikawa H, Mitsuhashi N, Sakurai H, Maebayashi K and Niibe H: The effects of p53 status and human papillomavirus infection on the clinical outcome of patients with stage IIIB cervical carcinoma treated with radiation therapy alone. Cancer 91: 80-89, 2001

34. Seo YR, Smith ML, Han SS, Fairbairn DW, O'Neill KL and Ryu JC: Mild hyperthermia-induced apoptosis is dependent on p53 in human lymphoid cells. Res Commun Mol Pathol Pharmacol 104: 285-292, 1999.

35. Guan J, Stavridi E, Leeper DB and Iliakis G: Effects of hyperthermia on p53 protein expression and activity. J Cell Physiol 190: 365-374, 2002

36. Ohnishi $\mathrm{K}$ and Ohnishi T: Heat-induced p53-dependent signal transduction and its role in hyperthermic cancer therapy. Int $\mathbf{J}$ Hyperthermia 17: 415-427, 2001. 